\title{
Reinforced Embankment - An Efficient Method to Stabilize Gotvand Powerhouse Upper Trenches
}

\author{
A. Zabihollah Zadeh, M. R. Zahedi, and M. H. Najdi
}

\begin{abstract}
Exposed hydroelectric power plant of Upper Gotvand Dam had required stabilization at eastern encompassing trenches. Necessity of establishment of power transmitting station upon these trenches and remarkable load exerted has made structure much more important. Basic surveys were accomplished, and then shotcrete and rock bolt sketch was replaced by reinforced embankment retaining wall because of some apparent advantages. Technical characteristics of structure were evoked based on bed peculiarities, structural behavior analysis, and required final attributes. Thus, embankment, galvanized belts, and facade wall precast concrete segments were characterized afterwards. Construction sequences were explained and major profits have been articulated. For instance, flexibility, considerable burden and settlement tolerances, and relatively easy and fast construction could be named.
\end{abstract}

Index Terms-Galvanized steel belts, precast segments, reinforced embankment, and retaining walls.

\section{INTRODUCTION}

Reinforced embankment had been devised in 1963 by Henry vidal, a French architect. This technique has recently been used for numerous constructional functions such as retaining walls, side spans of bridge piers; wave influenced coastal dikes, and reservoir for raw materials at mines.

It started by concrete segments' installation and continues by taking advantage of galvanized steel belts as a tensile supplementary element. Initial stabilizing sketch for eastern trenches of exposed powerhouse at elevation of about 105.5 to 127 was dry shotcrete. Excavation progress reveals remarkable magnitudes of low strength deposit layers at trenches. On the other hand power transmitting station has been designed upon, at elevation of about $127 \mathrm{~m}$, in which several heavy equipments will be installed and makes land slide much more intended. After experiments were conducted, decision was made to replace shotcrete by reinforced embankment with precast retaining wall [1]. As we mentioned before embedded metal belts in a strip fashion make mechanical properties of embankment to amplify, so that total tensile strength of structure is improved notably.

\section{METHODS}

\section{A. Qualitative Bed Survey}

Bed geotechnical identification is of utmost importance in

Manuscript received May 10, 2014; revised July 20, 2014.

A. Zabihollah zadeh is with Mahab Ghodss Consulting Engineering Company, Iran (e-mail: alizabihollah@yahoo.com). conjunction with structural requirements. Ordinary identification is consisted of in place tests for each 30 to 40 meter distant points using static penetrometer or every 60 to 80 meters by pressure meter tool. When construction is planned on a weak, high compressible bed, special identifications should be specified.

Penetrometer discriminates nonhomogeneous thickness of compressible zones. For this, test pits for every 60 meters, aside from undisturbed soil sampling as well as a vane shear test for each 40 meters is required. Underground water has to be monitored using piezometers as well.

\section{B. Seepage Protection}

Hydraulic condition of construction area should be considered and structure has to be protected from seepage because of two major following reasons;

1) Saturated soil makes tensile stress on metal belts to grow. Also softer soil causes friction between soil particles and belts to mitigate. This effect has to be regarded in structural design.

2) Probable presence of detrimental chemical agents in seepage water like salts, used for ice melting purpose.

Thus to prevent underground or precipitation water, enter the embankment, drainage material has to be accomplished beneath first embankment layer [2]. Drainage layer has to be executed at minimum slope of about $5 \%$ toward drainage pipe (collector) that is laid outside structure on facade's toe. Coherent execution of drainage layer is of paramount importance as well Fig. 1.

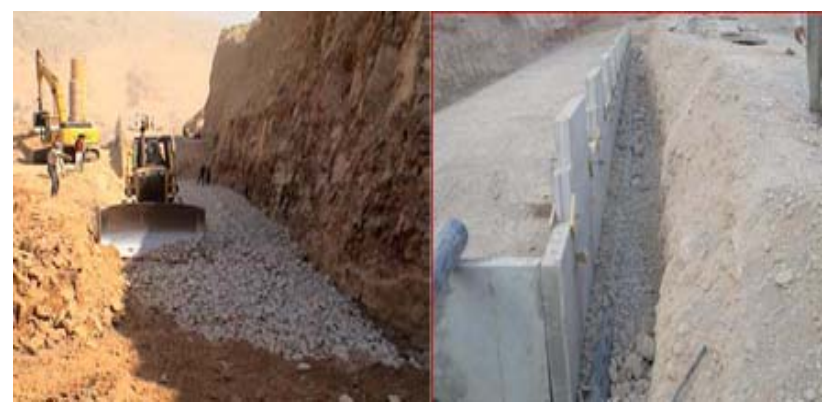

Fig. 1. Drainage system, beneath drainage layer (a) Collector pipe (b).

\section{Scheme and Geometric Characteristics}

General scheme and geometric attributes of structure is shown here in Fig. 2.

Parameters involved are $H 1=$ facade height, $D=$ facade's buried depth, and $L=$ belt length.

It is noticeable that in Gotvand powerhouse trenches mechanical height, $H$ is designed equal to $H 1$.

Buried height is designed to prevent both local failure in facade surroundings and soil punching shear at wall 
foundation, which depends on;

1) Freezing depth. Although at cold climates with higher freezing depths, other methods have to be applied.

2) Magnitude of collapse risk as a result of subsequent operations like excavating procedure behind the wall.

3) Wash out risk for foundation, specifically when water accumulates in front of retaining wall. If structure was founded on stiff, impermeable beds like stone or concrete basements and were not exposed to freezing, problem will exacerbate.

Facade height at our first floor is $7 \mathrm{~m}$. Since it is found on a weak bed, we opted to design buried height, of about $1.5 \mathrm{~m}$. Second, third, and fourth floors are $6 \mathrm{~m}$ height and have $0.5 \mathrm{~m}$ buried part because of higher strength and more compacted bed provision.

Precast concrete panels are settled on an even lean concrete at each individual floor to make wall construction accurate enough.

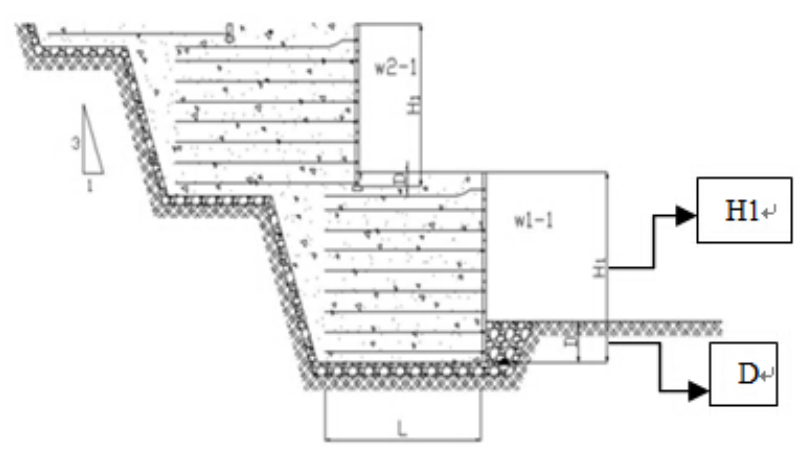

Fig. 2. General scheme, cross section, and major geometric features.

\section{Belt Length, Embankment Width Calculation}

Reinforced embankment that acts as a retaining wall should satisfy criterion of, $L \geq 0.7 H 1$, thus in first floor $L \geq$ $(0.7 \times 7=4.9 \mathrm{~m})$ and for other floors $L \geq(0.7 \times 6=4.2 \mathrm{~m})$ have been regarded (see Fig. 3).

Embankment has to be wide enough to cover belt length and makes operation of compacting machines possible as well.

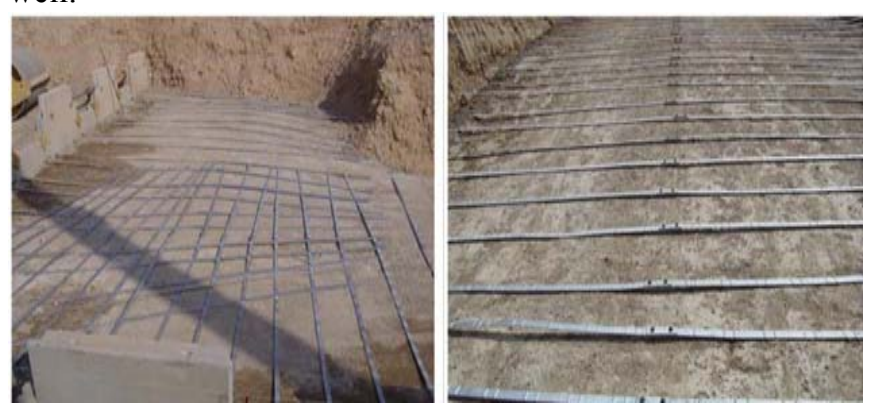

Fig. 3. Metal belts and respective embankment width.

\section{E. Structural Behavior}

Friction available between soil and belts mostly govern structural function that is influenced by soil characteristics, variable adhesion between soil and belts, and finally belts' tensile strength.

Field measurements on constructed structures have revealed normal stress linear distribution beneath structure except for wall adjacent. Thus we can take advantage of gravity wall principles for our structure [3]. Nevertheless flexibility of reinforced soil should be considered in structural external stability analysis [4], such as bed punching shear resistance in case of long belt usage.

To ascertain penetrating shear section, an assumed width for embankment mass equal to belt minimum length $(L)$, and minimum mechanical height for structure $(H 1)$ have to be regarded. Exerted forces could be defined as resultant vertical and horizontal forces $(R V, R H)$ and a torque $(M)$ as well (see Fig. 4).

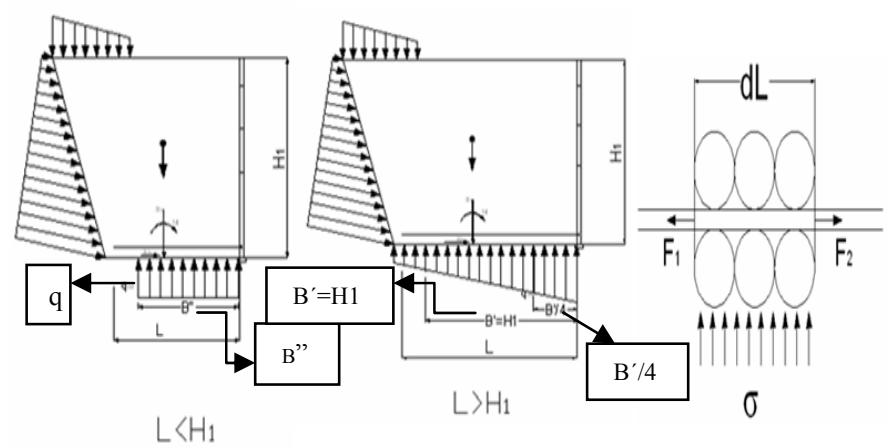

Fig. 4. Stress distribution (a, b), Soil particles-belt interaction(c).

If $L<H 1$, then normal reference stress $\left(q_{\text {Ref. }}=\right.$ stress per unit area) on bed can be calculated the same as spread foundations, "(1)". It is assumed that stress is distributed uniformly over foundation decreased width. $B^{\prime}$ is equal to structure mechanical height, $H 1$ and $B^{\prime \prime}$ can be evaluated as well, "(2)".

$$
q_{\text {Ref. }}=R_{V} /\left[B-\left(2 M / \underline{R}_{V}\right)\right]
$$

$B^{\prime \prime}=B-2\left(\mathrm{M} / R_{V}\right)(B=$ belt width and wall concrete panels' thickness)

If $L>H 1$, then normal stress distributes linear beneath embankment mass in a width equal to $L$. In order to control punching shear we are about to use the above stress diagram in part, which is matches the width $B^{\prime}=H 1$. This partial diagram is a basis on which reference stress should be evaluated.

Soil local behavior is illustrated as well. Friction originated shear strength between soil particles and belt surface, transforms exerted normal stress to tensile stress along belts (see Fig. 4(c)).

\section{F. Tensile Forces Distribution}

General view and embankment operation of Gotvand affiliated retaining wall could be seen in Fig. 5 .

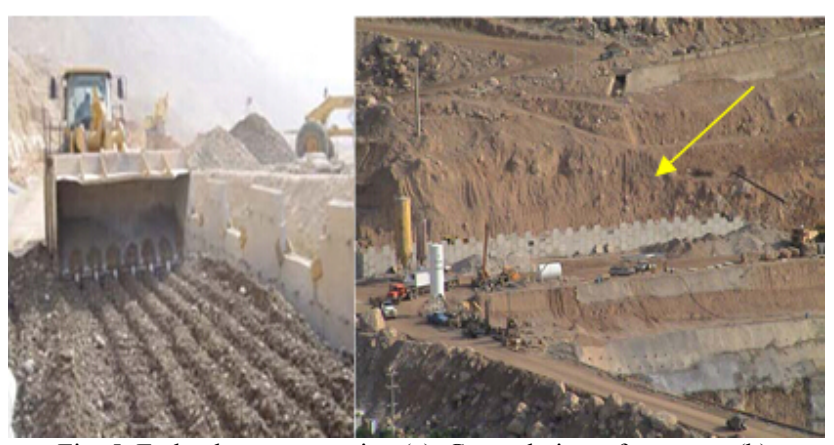

Fig. 5. Embankment operation (a), General view of structure (b).

Both empirical and experimental observations of several 
reinforced embankment retaining walls have illuminated that, maximum tensile line divides soil mass into active and passive zones in which soil exerts outward and inward shear stress onto belts' surface respectively.

As it is illustrated, geometric location of maximum tensile points at top surface is closer than $(0.3 \mathrm{H} 1)$ to retaining wall (see Fig. 6).

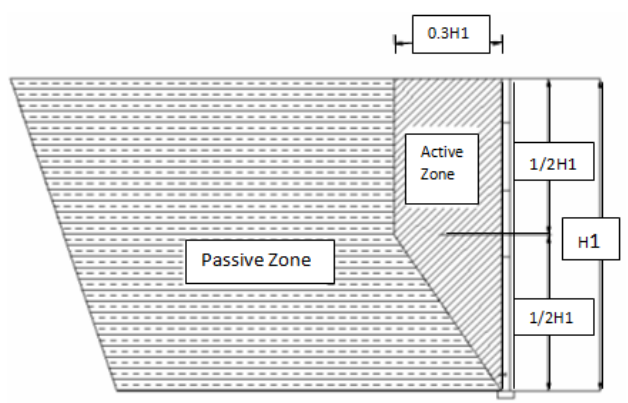

Fig. 6. Embankment, zone discrimination.

\section{FAILURE MECHANISMS}

Failure might be originated of some motives including belts' failure, cohesion deficiency between soil and belt surface, or external instability.

\section{A. Failure of Belts}

Strength shortage of belts as a major cause could be of following inducements;

1) Insufficient opted dimensions for belts.

2) Higher exerted forces in comparison with foreseen values.

3) Weakened sections of belts because of corrosion.

Tests have demonstrated, such failures gradually might grow along maximum tension line.

\section{B. Lack of Cohesion}

Deficit of friction coefficient makes shear strength between soil and belts' surface to decline.

That way tensile stress in belts exceeds shear resistance in conjunction with soil and makes belts to slide. Such slides can produce remarkable deformations in embankment and subsequently can result in failures.

In order to enhance friction coefficient we opted to use ribbed belts in Gotvand powerhouse project (see Fig. 7).

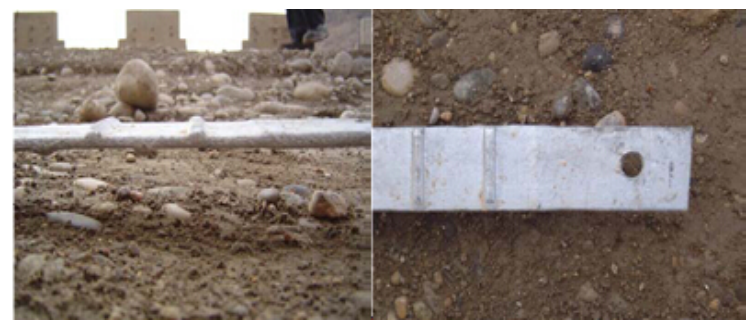

Fig. 7. Ribbed belts, applied to enhance cohesion.

\section{External Instability}

Weak, low strength bed soil or structure surroundings can cause basement or mass slide respectively [5].

It is noticeable that forces upon which structure undergoes, should be taken into account in structural design. Such forces are classified into three categories.

Permanent forces such as soil dead load, forces originated of variable agents like traffic or water related ones that mostly vary in time. And third type, incurred by occasional causes that influence structure sporadically.

Earthquake originated stress is an example of third category.

\section{REINFORCED EMBANKMENT COMPONENTS AND THEIR TECHNICAL ATTRIBUTES}

\section{A. Embankment Mechanical Properties}

Embankment could be constructed of either natural soil or industrial source materials. However organic soils are forbidden. For ribbed and smooth belts, soil internal friction angle $(\varphi)$ should be equal or more than $25^{\circ}$ and $22^{\circ}$ respectively to satisfy needs. This angle $(\varphi)$ has to be elicited of high rate direct shear test in saturated condition.

To make qualification conditions more practical, mentioned rules have been transformed to soil grading related criteria (see Table I).

TABLE I: MECHANICAL ATTRIBUTES FOR EMBANKMENT MATERIALS

\begin{tabular}{|c|c|c|c|c|c|c|}
\hline \multirow{7}{*}{$\begin{array}{c}\text { Materials } \\
\text { Finerthan } 75 \mu \mathrm{m} \\
(\%)\end{array}$} & $\leq 15 \%$ & & factory & echanica & properti & \\
\hline & \multirow{6}{*}{$>15 \%$} & \multirow{6}{*}{$\begin{array}{c}\text { Materials } \\
\text { finer } \\
\text { than } 15 \\
\mu \mathrm{m}(\%)\end{array}$} & $\leq 10 \%$ & \multicolumn{3}{|c|}{$\begin{array}{c}\text { Satisfactory mechanical } \\
\text { properties }\end{array}$} \\
\hline & & & \multirow{4}{*}{$\begin{array}{c}>10 \\
\& \\
\leq \\
20 \%\end{array}$} & \multirow{2}{*}{$\begin{array}{c}\text { Ribbed } \\
\text { belts }\end{array}$} & $\varphi \geq 25^{\circ}$ & Satisf. \\
\hline & & & & & $\varphi<25^{\circ}$ & Rejec. \\
\hline & & & & \multirow{2}{*}{$\begin{array}{c}\text { Smooth } \\
\text { belts }\end{array}$} & $\varphi \geq 22^{\circ}$ & Satisf. \\
\hline & & & & & $\varphi<22^{\circ}$ & Rejec. \\
\hline & & & $>20 \%$ & \multicolumn{3}{|c|}{ Rejected materials } \\
\hline
\end{tabular}

Since eastern trench materials do not meet requirements, it was partially replaced by proper materials to amplify $\varphi$ values [6]. Besides that we planned to use soil-cement mixture in first floor to enhance adhesion coefficient $(C)$ [7]. That way shear strength is increased $(\tau=C+\sigma \tan \varphi)$.

$100 \mathrm{~kg}$ cement per cubic meter materials was mixed in 5\% water by weight and compacted in layers of about maximum $37.5 \mathrm{~cm}$ thick.

\section{Belts}

Although plastic and polymer materials such as geosynthetics are rather suitable, however lack of enough field experience of their long life durability in our country, made us to use galvanized iron belts.

Galvanized steel has some beneficial features. Zinc coating protects steel against mechanical and chemical detrimental agents through cathode protection. Zinc provides sort of minute rate, gradual and uniform trend of steel corrosion during its life and impedes intense wearing.

Belts are $5 \mathrm{~mm}$ thick and $50 \mathrm{~mm}$ wide. $150 \mathrm{~mm}$ length galvanized clips are used at joints that have been connected by $($ HM12×3 (see Fig. 8 (a)).

\section{E. Facade}

Precast cross shaped concrete elements are produced in $(1.5 \mathrm{~m} \times 1.5 \mathrm{~m} \times 0.18 \mathrm{~m})$ as our standard segment with 1.1 tone weight. Some necessary miscellaneous panels were produced as well. Kind of vertical joints connect panels and provide horizontal flexibility. 
Vertical flexibility of wall is ensured by soft fillers laid in horizontal joints. These puzzle shaped panels have been reinforced by $\varphi 8,10$, and 12 ribbed bars. $350 \mathrm{~kg} / \mathrm{m}^{3}$ cement content is used to assure minimum compressive and tensile strengths of about 26 and $3.2(\mathrm{MPa})$ respectively in 28 days.

\section{F. Execution Sequences}

After excavating process and bed preparation were fulfilled, apron drainage layer and a precisely leveled lean concrete as a simple foundation for wall have been accomplished.

Then concrete panels were installed and wall has been established. In order to damp future active pressure of compacted layers, kind of supporting bolts by which joints are tighten were applied, specifically for initial rows (see Fig. 8 (b)).

Each $37.5 \mathrm{~cm}$ roller compacted layer was tested to check whether if it satisfies minimum density requirement or not. When test results become approved, parallel belts are laid on evenly smooth surface to ensure required contact and satisfy devised shear strength. Sequential process of layer compaction, belt embedding and installation of wall segments were continued to its ultimate elevation Fig. 9.

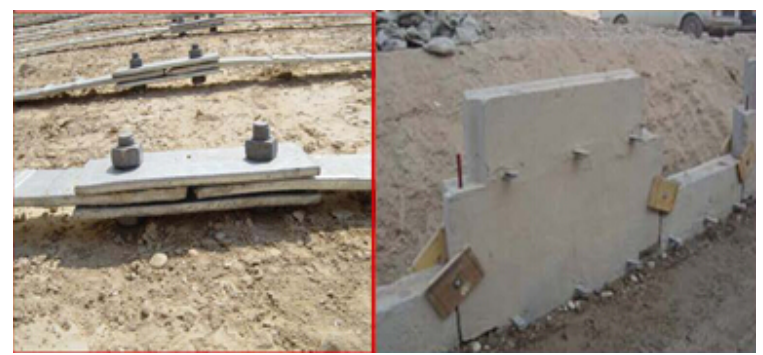

Fig. 8. Belts' clips (a), tightening bolts (b).

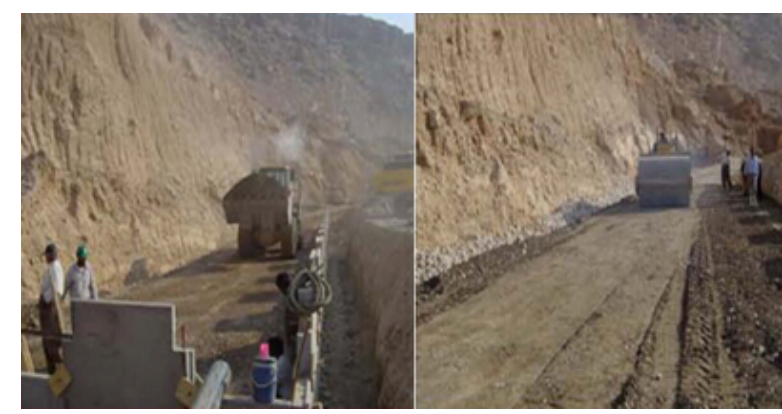

Fig. 9. Layer compaction.

\section{CONCLUSION}

Recent experience accompanied by previously accomplished studies and constructions can elicit following conclusions and assert pertaining privileges.

This structure is flexible and capable of being constructed on highly compressible soils. It doesn't require deep foundations and resist much more settlements than that of other alternative structures. It also is capable of bearing rather remarkable burdens such as Gotvand power transmitting station.

Reinforced embankment highly resists either static or dynamic forces including, earthquake or explosion forces, thermal stress in frigid or very hot climates, and wave impacts as well.

In comparison with shotcrete option, rock bolts are eliminated. Conversely Soil is mostly convenient as major component in this structure. Its relatively easy embankment operation could be accomplished by every at disposal soil machineries, which are available in ordinary workshops.

Taking advantage of easy to install, precast elements, and capability of consecutive, nonstop embankment operation for several layers make construction, much more progressive. (In comparison with cast in place, concrete retaining walls)

Structure is also aesthetic as well. For instance structure is highly consistent to vegetation and its facade design is optional as well.

\section{ACKNOWLEDGMENT}

Authors wish to thank technical cooperation of Mr. Hasani, Mr. Zafari, and Mr. Ansari.

Continuous helps of Prof. Akhoond Ali is so appreciated as well.

\section{REFERENCES}

[1] R. Jones and G. Swift, Design and Construction of a Reinforced Soil Embankment on Soft Soil, Golder Association and University of Salford Press, 2008.

[2] B. L. J. Mylleville and R. K. Rowe, "On the design of reinforced embankments on soft brittle clays," in Proc. the Geosynthetics, Atlanta, Georgia, vol. 91, pp 395-408, 1991.

[3] S. Duangkhae, D. T. Bergado, P. J. Baral, and B. T. Ocay, "Analysis of reinforced embankment on soft and hard foundations," in Proc. the ICE- Ground Improvement, vol. 167, no. 1, pp. 3-23, 2013.

[4] Y. Lin, J. D. Scott, and D. C. Sego, "Geogrid reinforced clay slopes in a test embankment," Geosynthetic International, ISSN 1072-63491, vol. 1, no. 1, pp. 67-91, 1994.

[5] R. Rowe and K. L. Soderman, "Reinforced embankments on very poor foundations," Geotextiles and Geomembrans, Elsevier Applied Science Publishers, vol. 4, pp 65-81, 1986.

[6] F. Masse, S. Pearlman, and R. A. Bloomfield, "Support of MSE walls and Reinforced embankments using ground improvement," Menard, Bridgeville and Earth Company.

[7] D. T. Bergado and G. A. Lorenzo, "Behavior of reinforced embankment on soft ground with and without jet grouted soil-cement piles," Asian Institute of Technology, Bangkok, Thailand, 2004.

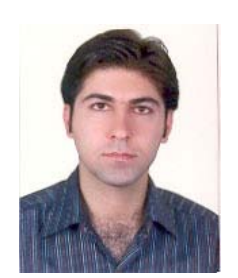

Ali Zabihollah Zadeh was born in Dezful, Iran in 1978 and he earned BSc. degree in irrigation from Shahid Chamran University of Ahwaz, Iran at 2001as first ranked graduate. He received the MSc. degree in irrigation-hydraulic structures at Shahid Chamran University with major studies on vortex flow hydraulicsat 2004.

$\mathrm{He}$ has been engaged as an instructor of Civil Department of Jundi Shapour University and Azad Universities in the area as well for three years. Statics, strength of materials, soil mechanics, elementary structural analysis, hydrometry, hydrology and geohydrology, surveying, construction materials and methods have been materials, instructed by first author. He cooperated with Karoon Agro-Industerial Company to monitor hydraulic structures available for six months, and he has been hired by Mahab Ghoddss Consulting Engineering Company till now. He acts as the Q.C. inspecting vice president in Upper Gotvand Dam and the head inspector of embankment at one of dam affiliated projects as well. 